\title{
Identidades y territorialidades. Un análisis desde los relatos de grupos de migrantes en Argentina ${ }^{\star}$
}

\author{
Identities and territorialities. An analysis from the stories of groups of \\ migrants in Argentina
}

\author{
Mercedes Mariano ${ }^{\star *}$ \\ Instituto de Investigaciones Arqueológicas y Paleontológicas del Cuaternario \\ Pampeano (INCUAPA). Programa Interdisciplinario de Estudios sobre el Patrimonio \\ Cultural "PATRIMONIA", del INCUAPA-U.E. CONICET
}

Recibido: 6 de enero de 2017. Aprobado: 15 de mayo de 2017.

\begin{abstract}
Resumen
El presente trabajo tiene como objetivo recuperar relatos de vida de grupos de migrantes para analizar cómo a través de ellos se van construyendo representaciones étnico-identitarias y territoriales dentro de un contexto sociocultural caracterizado por relaciones desiguales de poder. En este marco, se recuperan los relatos, testimonios y trayectorias de actores sociales que migraron desde Bolivia y se radicaron finalmente en ciudades consideradas de tipo intermedias del centro de la provincia de Buenos Aires, como Olavarría, Tandil y Azul, y se los inserta dentro de procesos más amplios de desterritorialización y reterritorialización.
\end{abstract}

Palabras clave: territorialidad, identidad, trayectorias migratorias.

Este artículo es resultado del proyecto "Estudio de las significaciones sociales del patrimonio cultural del partido de Olavarría, provincia de Buenos Aires. Propuesta metodológica para su visibilización y salvaguarda”. PIP Código 1122015 - 0100106 CO, aprobado por Res. de Directorio de Conicet №111 del 20 de enero de 2016.

* Licenciada en Antropología por la Universidad Nacional del Centro de la Provincia de Buenos Aires. Doctora en Antropología Social por la Universidad de Buenos Aires. Integrante del Instituto de Investigaciones Arqueológicas y Paleontológicas del Cuaternario Pampeano (INCUAPA) - Unidad Ejecutora del CONICET. Integrante del Programa Interdisciplinario de Estudios sobre el Patrimonio Cultural "PATRIMONIA", del INCUAPA-U.E. CONICET. Becaria posdoctoral del Consejo Nacional de Investigación Científicas y Técnicas (CONICET) 20152017. Correo electrónico: mercedes.mariano@gmail.com 


\begin{abstract}
This paper aims to restore life stories of a group of migrants to analyze how through them are built ethnic identity and territorial representations within a sociocultural context characterized by unequal power relations. In this context, stories, testimonies and trajectories of social actors who migrated from Bolivia and were finally settled in cities considered of intermediate type center of the province of Buenos Aires, such as Olavarria, Tandil and Azul, and inserts them into broader processes of deterritorialization and reterritorialization.
\end{abstract}

Keywords: territoriality, identity, migratory trajectories.

\title{
Introducción
}

El presente trabajo tiene como objetivo recuperar relatos y narrativas sociales de grupos de migrantes y descendientes para analizar cómo, a través de ellos, se van construyendo representaciones étnico-identitarias y territoriales dentro de un contexto sociocultural caracterizado por relaciones desiguales de poder.

La elección de trabajar con relatos de vida se debe a que estos "son el reflejo de una época y su riqueza radica en su valor performativo y metacomunicacional” (Briones y Golluscio, 1994, p. 114). Son interpretaciones acerca del pasado, formalizadas en un discurso construido en el presente, que suelen hacer alusión a un conjunto de eventos, lugares, personas y hechos que son seleccionados y construidos por quien narra a través de sus propios valores y formas de entender el mundo.

A través de ellos es posible comprender, entre otras cosas, cómo la ocupación de los territorios ha generado a lo largo del tiempo sentimientos de arraigo o de desarraigo. De hecho, la acción de habitar y poblar lugares se relaciona con los diversos sentidos y representaciones que se construyen en torno de la identidad social de un grupo. La concepción de la territorialidad, en términos de Curtoni (2004), sería el producto de un esquema de pensamiento particular que se relaciona con una trayectoria histórica, con una particular forma de percibir y pensar el entorno en su totalidad y con las relaciones sociales. De esta manera, "la territorialidad representaría una forma de pensar la realidad 
en un momento dado por un grupo determinado, y los territorios serían la manifestación o traducción de esa forma de pensar" (p. 92).

En este marco, recuperar los relatos y testimonios de actores sociales que migraron desde Bolivia y se radicaron finalmente en ciudades del centro de la provincia de Buenos Aires - como Olavarría, Tandil y Azul- posibilita abordar antropológicamente los procesos de desterritorialización y reterritorialización. También permite introducir un aporte ante la falta de estudios sistemáticos sobre procesos migratorios en ciudades intermedias ${ }^{1}$. Dichos procesos han generado a lo largo del tiempo una nueva interrelación entre lo global, lo nacional, lo regional y lo local, alterando las relaciones entre territorio, identidad y ciudadanía.

Por su parte, son muchos los autores que destacan la significatividad de la territorialidad en relación con la conformación de grupos/identidades étnicas (Bari, 2002; Giménez, 2005; Ringuelet, 1987; Bonfil Batalla, 1981; Barth, 1976; entre otros). De hecho, en las definiciones y caracterizaciones de los mismos se suele hacer alusión a:

(...) un territorio que es considerado una herencia común, como la tierra de los padres y de los antepasados, que es modelado por el trabajo de muchas generaciones, que funciona como vínculo material entre las generaciones pasadas y actuales y que es considerado no solo como un espacio de inscripción de la memoria colectiva, sino también como un referente simbólico de la identidad colectiva (Giménez, 2005, p. 20).

No obstante, atender a las identidades étnicas no implica hacer una reducción a la territorialidad. Todos los autores mencionados incorporan otros elementos como centrales y constituyentes de los mismos, como el lenguaje, el parentesco, la religión (Giménez, 2005), "las características adscriptivas y la identificación diacrítica de sus miembros en el sistema de valores y el campo de comunicación” (Ringuelet, 1987, p. 30). La profundidad histórica es otra dimensión que desarrolla Ringuelet (1987) y que se intervincula con la territorialidad en la medida que alude a una historia en común, al tiempo de una memoria ancestral (de una profundidad parental). La referencia a un pasado lejano, a un origen común mitificado, en muchas ocasiones se plantea como base de la legitimidad del grupo, posibilitando la acumulación de "capital intangible": conocimientos tradicionales, estrategias de lucha y resistencia, experiencias, actitudes (Bonfil Batalla, 1981, en Ringuelet, 1987, p. 33).

Las ciudades de tipo intermedias se caracterizan por tener una población que ronda entre los 70.000 y 150.000 habitantes. 
En este contexto amplio de nociones y perspectivas teóricas que existen en torno de la cuestión étnica -y que aquí se recupera brevemente a los fines del objetivo planteado-, se coincide con Bari (2002), quien resalta también la dimensión de dominación como elemento determinante del proceso histórico de interacción entre grupos hegemónicos y minoritarios (p. 151). La autora propone entonces que las identidades étnicas son construcciones sociales que se constituyen a partir de procesos de contrastación, pero fundamentalmente de confrontación con el otro. Esta es la razón por la cual no se podrían analizar independientemente de las relaciones intraétnicas e interétnicas, porque esos son los espacios de interacción temporal "donde se mantienen, se actualizan y renuevan las identidades" (p. 156).

Por todo ello, cabe aclarar que el abordaje metodológico de este trabajo presentó desafíos que surgieron a partir de la diversidad de experiencias de vida de los actores sociales entrevistados. Esto fue enriquecedor desde el punto de vista de la multiplicidad de visiones que pudieron recuperarse y analizarse, pero requirió de una adecuación particular en cada uno de los casos trabajados. Por ello, como se verá a continuación, los resultados obtenidos fueron cualitativa y sustancialmente diferentes. Para relevar las diversas voces y poder llevar a cabo una representación/descripción coherente de las trayectorias y relatos de los actores, se utilizaron métodos y técnicas etnográficas no directivas, como observaciones participantes, conversaciones y entrevistas (Guber, 2011; Gutiérrez y Roggi, 1999). Se trabajó también con documentos y fuentes escritas que pudieron aportar conocimientos, interpretaciones y narrativas de interés. En el Archivo Histórico Municipal de la ciudad de Olavarría, por ejemplo, se encontraron artículos publicados en la década de 1980 con la transcripción textual de entrevistas que se le hicieron a los primeros migrantes en radicarse en dicho lugar y que hoy ya no se encuentran presentes.

Entendiendo que los relatos son construcciones espacial y temporalmente situadas, se aclara que el trabajo de campo se llevó a cabo entre el 2008 y el 2012. Finalmente, se menciona que se contó con el consentimiento libre e informado de los entrevistados y se decidió reemplazar los nombres reales por ficticios para resguardar el anonimato de los actores.

\section{De relatos y desigualdades}

José nació a mediados de la década del 1940, en Potosí (a 164 km de Sucre). Se define como "hijo de la clase campesina" y considera que su historia es "como para hacer una película". 
La primera frase que expresó desde la entrada de su casa y con los brazos abiertos fue: "ahora sí llegó mi momento de transmitir aquello que por tanto tiempo se nos negó. Es el momento de hablar". Y, seguidamente, hizo mención de la persecución histórica que se llevó a cabo sobre los pueblos originarios y sobre su lengua, identificándose como uno de ellos.

En suspenso quedaron las preguntas, de quien entrevistó, que se hubieran dirigido a entender qué significaba para él ser "hijo de la clase campesina"; por qué consideraba que era su misión transmitir la historia; a qué se refirió al decir que "es ahora el momento"; y qué relación establecía entre ser "hijo de la clase campesina" y "ser parte de los pueblos originarios". Las respuestas, no obstante, fueron apareciendo a lo largo del relato.

La entrevista se llevó a cabo en su casa, sentados alrededor de la mesa redonda del living comedor, junto a la cocina. Su mujer estuvo presente a un costado, sin participar. El inicio de su relato se circunscribió a 1952, cuando, en sus términos, "se liberó de la esclavitud a Bolivia". No es casual que el relato de José comenzara en este período particular, porque su historia personal, así como la de su familia en Bolivia, se inscribe y entreteje en este contexto específico, que tiene a los campesinos como protagonistas de una reforma revolucionaria. En este sentido, cabe mencionar que en 1952 estalló en ese país una sublevación popular contra el orden económico y político vigente. La Gran Depresión y la derrota de Bolivia en la Guerra del Chaco no solo habrían puesto de manifiesto las limitaciones del modelo económico y político boliviano, sino que, además, habría generado una crisis económica e institucional. En consecuencia, en abril de ese mismo año la revolución se consolidó, siendo la reforma agraria uno de los instrumentos que permitió improvisar un foco de poder alternativo (Halperin Donghi, 1998, p. 48). En palabras del descendiente aymara Mamani Condori (1999), "fue la incorporación del indio a la república boliviana lo que trastocó la institucionalización de un Estado asentado en la discriminación racial, que se expresaba a través del voto calificado y que llevaba a tomar decisiones a un reducido grupo de privilegiados" (p. 48).

Los "latifundios, el trabajo en la tierra, el buey y el yugo tirando el arado que abre el surco en la tierra" son elementos que utiliza para construir una imagen del contexto histórico y del trabajo que realizaban los "campesinos esclavos de los señores terratenientes", como su padre. De hecho, la figura protagónica de su relato es la de su padre, ex combatiente de la Guerra del Chaco y proclamado, después, dirigente de aquel movimiento político que se comenzó a dar en el interior de la organización de los propios campesinos, y que luego tendría como resultados la reforma agraria y la revolución. Es decir, desde el inicio de la entrevista se comienza a delinear un escenario caracterizado por las relaciones sociales 
desiguales, donde la "resistencia" y "la revolución" comienzan a ser las manifestaciones más visibles de un grupo que se encuentra sometido a una condición de dominación/ subordinación.

En la reconstrucción de los hechos, él definió tres tipos de actores sociales que coexistían en aquella Bolivia de 1952: los "terratenientes, que son los que explotan a la clase campesina; los puebleros o cholos, que viven en el pueblo y no participan en las fiestas que realizan los campesinos durante los tres meses siguientes a finalizar la cosecha (es decir, durante los tiempos de ocio); y los campesinos". En sus palabras, estos últimos eran "los más bastardeados y discriminados... ordinarios en su forma de pensar, porque no los instruyeron... para que no se aviven (se ríe)".

Esta distinción por él elaborada posibilitó comenzar a entender dichas identificaciones (definiciones) como categorías sociales generadas en un momento y lugar determinado que deben ser necesariamente analizadas en sus connotaciones sincrónicas y diacrónicas. Como lo expresa Tamagno (1988), hay categorías étnicas, como en este caso la de campesino, "que se han generado en la desigualdad social. No comprender la relación entre la construcción de categorías étnicas y las situaciones de dominación/subordinación que ordenan a los grupos que las construyen conduce a no plantear que muchas de ellas han servido y aún sirven para legitimar acciones de dominación” (p. 57). De hecho, teniendo claro esto, es posible identificar los mecanismos por los cuales los individuos se definen a sí mismos y a los demás de acuerdo con las clasificaciones imperantes de la propia sociedad (Tamagno, 1988). Estas clasificaciones surgen, se construyen y definen históricamente porque en un momento determinado se tornó necesario dirigir alguna cuestión de acuerdo a ciertos intereses; en este caso, la de reproducir e imponer una representación de los campesinos y no otra (el campesino no instruido y que, por ende, no vota). Se trata de una imposición desde el exterior que se legitimaría desde la hegemonía, es decir, a partir de la aceptación de una concepción del mundo como propia, aún cuando resulte contraria a los intereses sociales de quien la adopta. Dicha hegemonía es necesaria para ejercer el poder porque detrás de ella hay un juego permanente de oposiciones alternativas que representan un antagonismo contra el poder (Gravano, 2008, p. 105).

Los cuatro años de facto que le siguieron a la introducción del sufragio universal y a la revolución del 1952 marcaron, en el relato de José, un quiebre decisivo que concluyó con la decisión de viajar hacia la Argentina. En sus palabras: "durante el gobierno siguiente (de facto), mi familia tuvo que exponerse a las posiciones más extremas y tremendas (...) fue allí que a mi padre lo amenazaron... que lo iba a colgar como a Villarroel... fueron muchas cuestiones las que hicieron que mi padre se cansara y se enojara, y decidiera venir 
a la Argentina con un hijo de dos años y yo de nueve"2. El resto del relato se contextualiza en Argentina y reconstruye la trayectoria hasta el asentamiento final de la familia en la ciudad de Tandil, provincia de Buenos Aires, Argentina (Mariano, 2014; 2015).

De este modo, el relato de José da cuenta de una historia atravesada por cuestiones políticas, sociales e ideológicas que marcaron, hasta el día de hoy, el modo de identificarse a sí mismo y a los suyos. De hecho, es posible observar cómo este actor construye su relato a través de estrategias discursivas que ponen en marcha un juego de interacciones que permiten, a través de la oralidad, aportar interpretaciones cualitativas de procesos históricos-sociales concretos (dominación/explotación, revolución, libertad del campesinado, inmigración, lucha y persecución político-ideológica). No obstante, quienes nacieron en Argentina vivieron un escenario diferente, sin una persecución política ni ideológica tan marcada como para constituirse en eje transversal de identificación. En este sentido, a través del trabajo de campo con otras generaciones se pudo comprobar una hipótesis planteada por Caggiano (2005), que indica que las trasformaciones en la percepción, experimentación y valoración que los migrantes (y sus descendientes) hacen de algunos ejes identitarios responden en parte a nuevas posibilidades de interpretación ofrecidas por el marco socio simbólico del contexto de destino (Mariano, 2015).

El otro relato que se recupera en este trabajo es el de Juana, una de las cuatro hijas de un migrante oriundo de la ciudad de Cochabamba (situada en el centro del país). Su testimonio -junto con el de sus hermanas- permitió introducir y comprender la profundidad histórica de las identificaciones bolivianas que han emergido con fuerza en otra ciudad del centro de la provincia de Buenos Aires: Azul. El resurgimiento de "lo boliviano" en la ciudad tiene directa relación, como se verá de aquí en adelante, con la historia de su familia paterna. A través de lo que recuerda y le fue transmitido, ella reconstruye el pasado y la niñez de su padre en Bolivia, expresando que "él vivía en un pueblito muy precario en las montañas. Su infancia la pasó allá hasta más o menos los 17 años. Era pastorcito de ovejas. Junto con su familia vivía de las quintas que hacían y de los animales que criaban. Ellos empleaban el trueque para intercambiar alimentos con las demás familias y, de vez en cuando, bajaban a la ciudad a vender algún animal para obtener dinero". Junto con el resto de sus hermanas, caracterizaron la infancia de su padre como "muy dura" y expresaron que él debía caminar "muchos kilómetros descalzo para poder ir a la escuela" y que recién se calzaban "su único par de zapatillas" para ingresar

2 Gualberto Villarroel fue un político y militar boliviano (presidente de la Junta Militar de Gobierno 1943-1944, presidente provisorio 1944-1945 y presidente constitucional desde 1945) asesinado y luego colgado públicamente en 1946 . 
a la misma. En aquel entonces, el máximo nivel de enseñanza era el sexto grado, "pero solamente el que podía lo terminaba”.

Todos estos elementos, que fueron apareciendo desde el inicio en tono de anécdota, introducen -como en el caso anterior- un escenario sociocultural desigual y conflictivo. Incluso ellas cuentan que su padre "no tenía documento de identidad". Acceder al mismo, así como a un pasaporte, implicaba inscribirse en el servicio militar, "ingresando a la colimba, como lo llamaban ellos". Esta era "la única manera de salir del país, por lo menos, legalmente. Mi papá, mintiendo con su edad, ingresó un año antes en la colimba, empujado por la desesperación de dejar su precaria vida y salir del país".

Hasta aquí es posible identificar en los relatos de estas mujeres a un actor social determinado ("pastor de ovejas") que se inserta dentro de un contexto geográfico específico (las montañas) y en un sistema económico basado en un modo de producción que implica la crianza y venta de animales, la agricultura doméstica y el trueque como sistema para adquirir productos. Se pone de manifiesto una situación en la cual los niños tienen acceso a una educación formal (la escuela) y a una no formal, que implica el aprendizaje y la práctica del trabajo en la unidad económica familiar. No obstante, el acceso al primer tipo de enseñanza, la formal, presenta claras restricciones para los niños y niñas de determinadas zonas geográficas. La distancia, así como la escasez de determinados recursos (el calzado, por ejemplo) y la necesidad de aportar al sostenimiento familiar se convierten en elementos significativos a la hora de señalar los procesos de inclusión y exclusión dentro del sistema escolar primario. A su vez, estas entrevistadas dieron cuenta de la existencia de un "tipo de vida precaria", "muy dura" y una contundente determinación, producto de "la desesperación" de su padre "por salir" del país. En este sentido, si bien la migración puede ser entendida como producto de una decisión personal, la misma es el resultado de una situación social que sería percibida como imposible de cambiar. Es decir, puede ser pensada como la manifestación de un descontento o como una estrategia (individual/familiar); sin embargo, las razones que los movilizaron hacia la decisión de partir resultan de procesos sociales e históricos signados por relaciones fuertemente desiguales entre los diversos segmentos de la sociedad. En la práctica, carecían de la potestad de ejercer sus derechos ciudadanos, ya que solo una vez cumplido el servicio militar era posible obtener el documento de identidad. En este contexto, resulta incluso paradójico pensar que la única vía legal para dejar su país haya sido a través de la acción de constituirse en "defensor" de la misma "patria" que finalmente abandonó. 
Juana expresa que, en su niñez, tuvo la oportunidad de ver y conocer a los amigos de su padre, que vinieron con él desde Bolivia hasta Azul: "Era algo tan lindo, porque se juntaban cada uno con sus familias y hablaban en quechua y bailaban sus bailes. Es una lástima que nunca nos haya enseñado". Un silencio prolongado le sigue a esta afirmación. La muerte de su padre es muy reciente, y con su partida desaparecen -desde su miradaun conjunto de conocimientos y prácticas que ellas hubieran preferido aprender para atesorar y transmitir a las generaciones siguientes. Ahora bien, si el análisis se redujera a creer que con la muerte de un miembro del grupo desaparece todo ese abanico de saberes, se perderían de vista las estrategias sociales y simbólicas que son reactivadas a partir de un cierto número de representaciones que vienen a resignificar esas manifestaciones. En este sentido, no ha de subestimarse la capacidad creativa de los actores sociales; por el contrario, si bien la entrevistada se lamentó por lo que ella consideraba perdido, ello definitivamente no le impidió crear una comparsa en la ciudad, donde se recrean las danzas tradicionales de los carnavales de Bolivia, como la Morenada y la Diablada, entre otras (Mariano, 2014).

Por último, y para ampliar el campo, se recuperan aquí los relatos que se insertan en otra ciudad del centro de la provincia de Buenos Aires, Olavarría. Si bien no fue posible acceder metodológicamente a los relatos de los primeros migrantes de manera directa, fue posible encontrar en el Archivo Histórico de la Municipalidad de la ciudad documentos bibliográficos que datan de 1988, que fueron relevados y escritos por una historiadora amateur. La revisión y análisis de dichos documentos permitieron no solo reconstruir un contexto específico, sino también recuperar un conjunto de representaciones propias de la primera generación de migrantes bolivianos en llegar a la ciudad en la década del 50. A partir de las narraciones, descripciones y transcripción de entrevistas efectuadas por la mencionada historiadora fue posible determinar que, en 1954, habrían llegado los primeros migrantes de procedencia boliviana, siguiendo las indicaciones de un técnico en explosivos que un importante centro industrial de la región -fábrica Loma Negrahabía contratado en Potosí. A esto se sumó la invitación de una empresaria boliviana, dueña de una calera, para venir a trabajar.

"La búsqueda de un mejor porvenir económico" como el motivo principal que explica el comportamiento de migrar está también presente en las entrevistas llevadas a cabo en el trabajo de campo de los últimos años. "El campo de la construcción, las cementeras locales y -en los últimos 10 años- la agricultura (las quintas) generaron que los residentes bolivianos consiguiéramos trabajo efectivo" (Matías, comunicación personal, septiembre de 2011). El "boca en boca" funcionó para reunirlos en un mismo territorio, como lo 
expresa un joven; "hay residentes desde hace 50 años y, sin embargo, no son muchos los apellidos diferentes que uno puede encontrar".

Entre los años 1987 y 1993, la mencionada historiadora entrevistó a algunas de las mujeres bolivianas con la convicción de que su registro era importante para entender los cambios que se aceleraban en el seno de la comunidad y, además, porque se trataba de migrantes diferentes de los que, hasta ese momento, había conocido: "Diferentes por ser mujeres y latinoamericanas, y por integrar una corriente nueva, de la segunda mitad del siglo $\mathrm{XX}$. Son las que no llegan en barcos o aviones, sino en micros y trenes, en viajes largos y agotadores" (Alonso, 2005, p. 291). "Eran mujeres de pelo oscuro y largo, recogido en una trenza o una cola, de polleras anchas y camisas blancas que se abrían a lo desconocido con una lentitud gloriosa", comenta hoy Alonso, y concluye: "Son aquellas inmigrantes que no hubieran dejado su tierra natal si no hubiese sido por la falta de trabajo" (Ana, comunicación personal, Olavarría, 2008).

En este contexto, aparecieron en los discursos claras referencias que aludían tanto a "las fuerzas de expulsión" (carencia de oportunidades laborales y económicas) que determinaron la decisión de emigrar como a las "fuerzas de atracción" que ejercieron Argentina -y específicamente Olavarría- como lugares de destino. Como explicaba Angélica: "Cuando sos pobre no hay perro que no te ladre. Ser pobre es feo, pero saber que no vas a mejorar y que tus hijos y nietos tampoco, es peor" (citado en Alonso, 2005, p. 293). Se dibujaba, de este modo, el escenario específico y conflictivo que motivó la decisión de "partir". En palabras de uno de los migrantes por ella entrevistado: "Los males son la pobreza, la tierra que no alcanza y hay que venirse a donde se pueda. En mi pago, Potosí, fue el agotamiento del mineral lo que mandó a tantos afuera" (citado en Alonso, 2005, p. 301).

Como puede observarse a partir de estas fuentes, las identidades bolivianas comenzaron a construirse en un espacio con una estructura social signada por la desigualdad. Estos discursos, como bien lo expresa Tamagno (1997), son portadores de "contenidos comunicacionales, cognitivos y simbólicos que no son ajenos al espectro de poder de la sociedad, sino que expresan relaciones de dominación/subordinación. Sitúan la identidad en el campo de las relaciones sociales, de las relaciones de poder, de las luchas simbólicas, las negociaciones y la lucha por los espacios en un mundo donde ya no quedan espacios vacíos" (p. 190). 


\section{La territorialidad y la identidad étnica en los relatos: a modo de discusión}

El estudio de la migración boliviana en Argentina ha sido abordado por investigadores de distintas formaciones y desde diferentes perspectivas. De hecho, los procesos migratorios se convirtieron en el eje de muchas investigaciones en diversos campos, a saber: la geografía cultural, la sociología y la antropología, entre otros. La mayoría de estos estudios tienden a separar en etapas los procesos migratorios y proponen que los desplazamientos de poblaciones desde Bolivia tienen una larga historia y son de gran relevancia para ese país. Estas investigaciones no se detienen, sin embargo, en una simple cronología de eventos migratorios, sino que indagan, además, en las razones que los generaron. Es decir, intentan dar cuenta de por qué, en determinado momento, se genera un gran movimiento de poblaciones desde Bolivia y qué condiciones socio-económicas se están dando en Argentina para convertirse en un posible punto de llegada de estos grupos que emigran.

Por su volumen y persistencia en el tiempo, la migración de los bolivianos a la Argentina ha sido un fenómeno social importante que podría deberse, entre otras cosas, a la débil oferta de oportunidades económicas, sociales y de promoción cultural que se daba en Bolivia (Almandoz, 1997; Zalles Cueto, 2002; Caggiano, 2005; Sassone, 2007). En este sentido, las migraciones poblacionales habrían comenzado a constituirse en proyectos socioculturales de búsqueda de recursos y estrategias cada vez más trascendentes que devinieron en procesos socio-históricos de transformación de las sociedades (Zalles Cueto, 2002). A su vez, el traslado de estos pobladores a la Argentina ha sido calificado como una "estrategia de vida y la decisión de migrar es una opción más en un contexto de movilidad espacial y economías diversificadas que han caracterizado históricamente a amplios sectores del occidente boliviano" (Dandler y Medeiros, 1985, pp. 56-58).

En este marco amplio se inserta la recuperación de las voces de quienes fueron protagonistas para profundizar el análisis de estos procesos sociales que no han sido sistemáticamente identificados en ciudades consideradas de tipo intermedias. Recuperar los relatos sobre las trayectorias migratorias y la procedencia de los individuos y de las familias que emigraron desde Bolivia y se radicaron, finalmente, en Olavarría, Tandil y Azul, permite poner de manifiesto el contexto conflictivo en el que se habría insertado la misma decisión de migrar. Esto implicó "procesos de descontextualización y recontextualización” (Prats, 2007, p. 20) equiparables a los que Kriger (2009) denomina procesos de desterritorialización y reterritorialización. En estos procesos se constituyeron 
nuevos campos culturales con otras formas de funcionamiento, acceso y legitimación, en las que las redes de comunicación jugaron un rol trascendental.

Apelar a los relatos de las primeras generaciones permitió poner en escena variables ideológicas, políticas, económicas y culturales que incidieron en la decisión de partir de Bolivia. Como lo expresa Grimson (2005), "la aparición constante de pequeños relatos en las entrevistas (...) indica que los propios actores efectúan una reflexión, que se presenta narrativamente, sobre situaciones de encuentro, negociación y conflicto..." (p. 44). De este modo, pudo saberse que los primeros migrantes en llegar a estas ciudades salieron de Bolivia "expulsados" por una realidad que deseaban modificar. Los que llegaron a Olavarría, por ejemplo, se vieron en la necesidad de migrar debido a la pobreza, como pudo observarse en el testimonio de una mujer: "Ser pobre es feo, pero saber que no vas a mejorar y que tus hijos y nietos tampoco, es peor". En el caso de Tandil, a través del testimonio de José se evidenció un proceso diferente y consecuente con una reivindicación política, como lo fue la de los campesinos en 1952. En este caso, si bien hay una explotación por parte de terratenientes, se da un intento revolucionario por cambiar el orden establecido en Bolivia que, de hecho, se produce en materia de participación ciudadana, distribución de tierras y derechos humanos. Sin embargo, esto pronto se ve sofocado por un golpe de Estado y seguido de una persecución político-ideológica que trajo como consecuencia la voluntad de salir del país. Finalmente, una de las trayectorias relevadas en Azul da cuenta de un contexto social caracterizado por la precariedad, condiciones de vida muy duras y una "desesperación" por salir de Bolivia en busca de mejores condiciones de vida.

Desde un análisis microsocial, podría decirse que pudo haber tantos motivos para migrar como relatos e interlocutores. Sin embargo, desde un análisis macro pudo advertirse que en todos los casos hay un disparador simbólico de confrontación. El país natal es caracterizado a través de imágenes fragmentadas, donde las relaciones sociales están marcadas por niveles de exclusión, subordinación, desigualdad y, por ende, de conflictos sociales y políticos que se perciben como difíciles de superar. En contraste, Argentina como destino toma fuerza y se potencia a través de un discurso que lo promueve por ser un país al que se puede ir a trabajar. La variable laboral se convirtió, entonces, en el eje ordenador de la migración misma y de los espacios ocupados por estos grupos dentro de las provincias y ciudades argentinas. Es decir, a través de esta narrativa fue posible identificar los motivos que influenciaron en la decisión de migrar. En el caso narrado por José, se trató de una variable político/ideológica que repercutió directamente en el cotidiano de una familia, alterando cuestiones laborales, económicas y sociales. Lo interesante es señalar que este tipo de información posibilita ampliar el análisis sobre 
la dinámica de los procesos migratorios sin reducir las explicaciones a una causalidad exclusivamente económica, es decir, a la búsqueda de nuevas o mejores fuentes de trabajo.

En este contexto de movilidad espacial se pueden advertir las diversas relaciones que se han construido entre diferentes grupos étnicos a lo largo del tiempo (Tamagno, 1988, p.51). Esta historia jamás estuvo desligada de las relaciones de poder, de las relaciones de pertenencia/exclusión y dominación/subordinación que se establecieron entre las personas y los grupos, que se expresan tanto a nivel de las prácticas como a nivel de las representaciones (Tamagno, 1988, p.52).

En suma, el grupo étnico se recupera y aborda en este trabajo como una categoría analítica que posibilita una aproximación a las diversas dimensiones sociales de un grupo en cuestión, y permite entender teóricamente cómo operan tanto los vínculos materiales como los referentes simbólicos. El uso de esta categoría posibilita pensar el pasado, su reinterpretación en el presente, el rol de los territorios, el lenguaje y el parentesco, entre otros, como construcciones sociales no pacíficas ni homogéneas, sino como organizaciones y construcciones problemáticas. En este sentido, como lo expresa Grimson (2005), ningún grupo humano es esencialmente o naturalmente étnico. Dicha categoría refiere a los modos en que un grupo se vincula con los otros en los diversos momentos sociohistóricos. "Las adscripciones identitarias no están determinadas por la sangre ni por el lugar de nacimiento -en Bolivia hay 'nativos' que se definen étnicamente y no nacionalmente (...)" (p. 184). Por ello resulta necesario, para analizar los procesos identitarios, explorar los modos en los que se constituyen como grupo y los sentidos que entran en juego, así como "los relatos que dan cuenta de su pertenencia, de su historia ..." (p. 184). Como lo expresa Lowenthal (1985), "el tiempo nos rodea y satura. Cada escena y cada acción tienen un contenido residual de tiempos pasados. Toda la conciencia que tenemos del presente se basa en las percepciones y actos del pasado. Siglos de tradición subyacen en cada instante de percepción y creación". Por ello, el pasado es integral a la identidad y se debe entender que ni el pasado ni la identidad son fijos y estables, sino que ambos necesitan adaptarse "a las presiones implacables del cambio".

En este contexto, como se ha venido desarrollando desde el comienzo, el territorio es un concepto importante que posibilita entender las identidades sociales territorializadas y permite pensar los fenómenos de arraigo y de apego, así como los sentidos de pertenencia y la movilidad, entre otros. El territorio es "territorio apropiado" (en Giménez, 2001, p. 6) y entenderlo de esta manera implica reconocerlo como un campo producido, regulado y protegido, atravesado por conflictos de diferentes grupos de poder. Es decir, la territorialidad resulta, en los términos de Giménez, indisociable de las relaciones 
de poder. Si bien dicha apropiación se puede dar en términos de variables utilitarias y funcionales, en este artículo se pone el foco en su dimensión simbólica y cultural. Es decir, cuando el territorio es reconocido como un lugar de inscripción de una historia (como la de José), la tierra de los ancestros, recinto sagrado, patrimonio valorizado o referencia de un grupo, se está visibilizando su carácter simbólico y cultural. Esta dimensión es de "capital importancia" para comprender cómo las territorialidades étnicas se construyen y resignifican a lo largo del tiempo.

De hecho, a medida que los migrantes se fueron asentando en territorio argentino, comenzaron a desarrollar diversas estrategias para adquirir trabajo, vivienda y documentación, así como para construir lugares propios desde donde comenzar a manifestar prácticas socioculturales en el nuevo contexto urbano. En este sentido, en las ciudades existen múltiples ámbitos de producción y reconstrucción de identidades vinculados a la "colectividad boliviana". Se trataría, en términos de Grimson (2000), de un "tejido social diverso" y disperso por distintas zonas, que incluye bailantas, restaurantes, fiestas familiares y barriales, ligas de futbol, programas de radio, asociaciones civiles, publicaciones, ferias, festividades, carnavales y comercios de diferente clase que informan sobre múltiples espacios vinculados con la identidad étnica boliviana. Es más, este entramado parece constituir otro mundo, diferente de la ciudad mayoritaria y las propias ciudades bolivianas, y que, sin embargo, vive y crece en permanente relación con ambas (Grimson, 2000, ver Mariano, 2015, p. 50).

\section{Referencias bibliográficas}

Almandoz, M. (1997). Inmigración limítrofe en Tandil: Chilenos y Bolivianos en los años noventa. Estudios migratorios latinoamericanos, 12 (37), 491-520.

Alonso de Rocha, A. (2005). Inmigrantes sociedad anónima. Olavarría, Argentina: Leviatán.

Bari, M. (2002). La cuestión étnica: aproximación a los conceptos de grupo étnico, identidad étnica, etnicidad y relaciones interétnicas. Cuadernos de Antropología Social, 16, 149163.

Barth, F. (1976). Los grupos étnicos y sus fronteras. D.F., México: Fondo de Cultura Económica. 
Bonfil Batalla, G. (1989). Identidad nacional y patrimonio cultural: los conflictos ocultos y las convergencias". En R. Ceballos (comp.), Antropología y políticas culturales. Patrimonio e identidad (pp. 43-52). Buenos Aires, Argentina: Departamento Nacional de Antropología y Folklore.

Briones, C. (1993-1994). Con la tradición de todas las generaciones pasadas gravitando sobre la mente de los vivos: usos del pasado e invención de la tradición. Revista Runa. Archivo para las ciencias del hombre, XXI, 99-129.

(1998). (Meta)cultura del estado nación y estado de la (meta)cultura: repensando las identidades indígenas y antropológicas en tiempos de post-estatalizad. Serie Antropológica. Brasilia: Departamento de Antropología, Universidad de Brasilia.

Briones, C., Cordeu, E., Olivera, M. y Siffredi, A. (1990-92). Reflexiones para el estudio de la cuestión étnica. Relaciones, XVIII, 53-64.

Briones, C. y Golliscio, L. (1994). Discurso y Metadiscurso como procesos de producción cultural. Actas de Jornadas de Antropología de la Cuenca del Plata y II Jornadas de Etnolingüística (pp. 114-124). Universidad Nacional de Rosario.

Caggiano, S. (2005). Lo que no entra en el crisol. Inmigración boliviana, comunicación intercultural y procesos identitarios. Buenos Aires: Prometeo.

Curtoni, R. (2004). Territorios y territorialidad en movimiento: la dimensión social del paisaje. Revista Etnia, 46-47, 87-101.

Dandler, J. y Medeiros, C. (1985). Migración temporaria de Cochabamba, Bolivia, a la Argentina: patrones e impacto en las áreas de envío. Cochabamba, Ceres.

Fortuna, C. (1998). Las ciudades y las identidades: patrimonios, memorias y narrativas sociales. Alteridades, 16, 61-74.

Giménez, G. (2001). Cultura, territorio y migraciones. Aproximaciones teóricas. Alteridades, 22, 5-14.

(2005). Teoría y análisis de la cultura. Intersecciones, 5, 1-371.

(2007). Estudio sobre la cultura y las identidades. México: CONACULTA-ITESO. 
Gravano, A. (2008). La cultura como concepto central de la Antropología. En Chiriguini, M. (comp.), Apertura a la Antropología. Alteridad, cultura, naturaleza humana (pp. 81122). Buenos Aires: Proyecto Editorial.

Grimson, A. (2005). Relatos de la diferencia y la igualdad. Los bolivianos en Buenos Aires. Buenos Aires: EUDEBA.

Guber, R. (2011). La etnografía. Método, campo y reflexividad. Buenos Aires: Siglo XXI editores.

Gutiérrez, P y Roggi, C. (1999). Encuentros y desencuentros. Reflexiones sobre el trabajo de campo. En N. Giarraca (comp.), Estudios rurales. Temas, problemas y estrategias metodológicas (pp. XX). Buenos Aires: La Colmena.

Halperin Donghi, T. (1998). Historia Contemporánea de América Latina. Madrid: Alianza Editorial.

Kriger, M. (2009). Introducción al concepto y la problemática de la globalización. En Globalización, consumos e identidades en América latina, CAICYT CONICET Cursos, Área ciencias sociales (http://ecursos.caicyt.gov.ar).

Lowenthal, D. (1985). The past is a foreign Country. Cambridge: Cambidge University Press.

Mamani Condori, C. (1999). History and prehistory in Bolivia: what about the indians? En R. Layaton y Unwin Hyman (comp.), Conflict in the archeology of living traditions (pp.4659). Londres: Unwin Hyman.

Mariano, M. (2011). Patrimonio intangible e identidad: representaciones bolivianas en Olavarría, provincia de Buenos Aires, Argentina. Intersecciones en Antropología, 12, 83-94.

- (2014). De representaciones, prácticas y fiestas bolivianas en las ciudades de Azul, Olavarría y Tandil, provincia de Buenos Aires. Un análisis desde la perspectiva del patrimonio cultural inmaterial. Tesis de doctorado no publicada, Universidad de Buenos Aires. Facultad de Filosofía y Letras.

(2015). Acerca de la identidad boliviana en Argentina. Un análisis de tres casos de estudio en la provincia de Buenos Aires, Argentina. Revista de Antropología y Arqueología ANTIPODA, 22, 45-64.

110 Si Somos Americanos. Revista de Estudios Transfronterizos 
Prats, LL. (2007). Antropología y patrimonio. Barcelona: Editorial Ariel.

Ringuelet, R. (1987). Procesos de contacto interétnico. En Ringuelet, R. (comp.), Procesos de contactos interétnicos (pp. 13-44). Buenos Aires: Ediciones búsqueda.

Sassone, S. (2007). Migración, territorio e identidad cultural: construcción de "lugares bolivianos". Población de Buenos Aires. Revista semestral de datos y estudios demográficos publicada por la Dirección General de Estadística y Censos, 4 (6), 9-28.

Tamagno, L. (1988). La construcción social de la identidad étnica. Cuadernos de Antropología, 2, 48-60.

- (1997). La construcción de la identidad étnica en un grupo indígena en la ciudad. Identidades y utopías. En Bayardo R. y Lacarrieu, M. (eds.), Globalización e Identidad Cultural (pp. 183-198). Buenos Aires: Ediciones CICCUS.

Zalles Cueto, A. (2002). El enjambramiento cultural de los bolivianos en la Argentina. Nueva Sociedad, 178, 89-103. 